\title{
Effect of continuous use of metformin on kidney function in diabetes patients with acute myocardial infarction undergoing primary percutaneous coronary intervention
}

\author{
Qi Yu, Jia-Jia Zhu and Wen-Xian Liu*
}

\begin{abstract}
Background: Diabetes patients presenting with ST-segment elevation myocardial infarction (STEMI) scheduled for primary percutaneous coronary intervention (PCI) have an increased risk of contrast induced-acute kidney injury (ClAKI). The effects of continuous use of metformin on kidney function are still controversial in patients submitted to primary $\mathrm{PCl}$. This study aimed to assess continuous metformin therapy on kidney function in diabetic patients undergoing coronary intervention.

Methods: Two hundred eighty-four patients with metformin-treated diabetes, who underwent coronary intervention within $24 \mathrm{~h}$ for STEMI, were enrolled in the retrospective study. All the patients had estimated glomerular filtration rate (eGFR) of $>30 \mathrm{~mL} / \mathrm{min} / 1.73 \mathrm{~m}^{2}$. According to the physicians' decisions after admission, 119 patients continued metformin treatment after primary $\mathrm{PCl}$, while 165 patients discontinued it $>48 \mathrm{~h}$ after the procedure. Serum creatinine was collected at admission and within $48 \mathrm{~h}$ post primary $\mathrm{PCl}$ to evaluate the incidence of $\mathrm{Cl}$-AKI. We performed a multiple logistic regression analysis to examine the determinants of $\mathrm{Cl}$-AKI.

Results: No statistical difference in $\mathrm{Cl}$-AKI incidence between the continuous and the discontinuous metformin group $(12.6 \%$ vs $10.3 \%, p=0.545)$. Multivariable logistic regression analysis indicated eGFR $\leq 60 \mathrm{ml} / \mathrm{min} / 1.73 \mathrm{~m}^{2}[p=$ 0.025, OR: 3.131; 95\% Cl (1.156-8.482)] and contrast volume [ $p=0.002$, OR: 1.010; 95\% Cl (1.004-1.016)] were predictive factors of $\mathrm{Cl}$-AKI. Metformin therapy was irrelevant to CI-AKI [ $p=0.365$, OR: 0.698; 95\% Cl (0.320-1.521)]. No case of lactic acidosis was found in this study. Besides, the study supported discontinuation of metformin was not beneficial for patients' blood glucose control after admission.
\end{abstract}

Conclusions: The study indicated that the metformin continuation after primary PCI for STEMI in diabetic patients with eGFR $>30 \mathrm{ml} / \mathrm{min} / 1.73 \mathrm{~m}^{2}$ did not increase the risk of Cl-AKI.

Keywords: Contrast induced-acute kidney injury, Metformin, ST-segment elevation myocardial infarction

* Correspondence: 18911662882@163.com

Department of Cardiology, Beijing Anzhen Hospital, Capital Medical

University, Beijing 100029, China

C C The Author(s). 2020 Open Access This article is licensed under a Creative Commons Attribution 4.0 International License, which permits use, sharing, adaptation, distribution and reproduction in any medium or format, as long as you give appropriate credit to the original author(s) and the source, provide a link to the Creative Commons licence, and indicate if changes were made. The images or other third party material in this article are included in the article's Creative Commons licence, unless indicated otherwise in a credit line to the material. If material is not included in the article's Creative Commons licence and your intended use is not permitted by statutory regulation or exceeds the permitted use, you will need to obtain permission directly from the copyright holder. To view a copy of this licence, visit http://creativecommons.org/licenses/by/4.0/ The Creative Commons Public Domain Dedication waiver (http://creativecommons.org/publicdomain/zero/1.0/) applies to the data made available in this article, unless otherwise stated in a credit line to the data. 


\section{Background}

As the first-line therapy of type 2 diabetes mellitus (T2DM), metformin is applying to nearly one-third of diabetes patients worldwide [1]. Therefore, in urgent situations, such as acute myocardial infarction, many of them cannot withhold the metformin prior to percutaneous coronary intervention (PCI)-related contrast medium administration [2]. Cleared by the kidneys, metformin is accumulated in circumstances when kidney function is deteriorated, such as contrastinduced acute kidney injury (CI-AKI), which may lead to lactic acid accumulation. Although metformin associated with lactic acidosis (MALA) has a reported mortality of 30$50 \%$, it is a rare disease with an estimated incidence of $1-5$ cases per hundred thousand people [3]. However, previous studies have shown that in most cases, metformin therapy may be merely concomitant and may not have a causal role at all [4].

ST-elevation myocardial infarction (STEMI) patients with CI-AKI after coronary stent implantation had longer hospital stays, increased adverse cardiovascular outcomes, and higher mortality [2]. As the direct toxicity of contrast media, the high thrombogenic state, inflammation, and the decrease in renal perfusion, patients submitted to primary PCI for STEMI are at high-risks for CI-AKI, [5]. According to different definition, the incidence of CI-AKI can range from approximately 6.4 to 27.7\% in STEMI patients after primary PCI [6].

Because of the post-procedural risk-MALA and CIAKI in diabetic patients submitted to PCI for STEMI, the guidelines are inconsistent on whether to continue metformin in patients undergoing PCI [7-10]. Currently, studies had concluded that initiation of metformin $\leq 3 \mathrm{~h}$ after primary $\mathrm{PCI}$ and chronic metformin therapy before primary PCI had no influence on CI-AKI in STEMI patients $[2,11]$. However, there is no clinical data about the continuation of metformin treatment during the primary PCI period in diabetic patients with STEMI, and the effects of metformin on the kidneys are still widely debated in patients exposed to contrast agents $[12,13]$.

The objective of the study to was to evaluate the influence of continuous metformin therapy on kidney function after coronary intervention for STEMI. In the meantime, the independent predictors of CI-AKI were explored.

\section{Methods}

\section{Patients and study design}

A single-centre retrospective study in a cohort of allcomers with T2DM undergoing primary PCI for STEMI was performed between January 2008 and December 2018 in the Department of Cardiology of Beijing Anzhen Hospital. All patients received metformin therapy before PCI. STEMI and T2DM are defined depending on the current guidelines $[8,14]$. The exclusion criteria included: patients without PCI, deficient of creatinine data, end-stage kidney disease (estimated glomerular filtration rate $<30 \mathrm{ml} / \mathrm{min} / 1.73 \mathrm{~m}^{2}$ ), respiratory failure, severe infections, liver disease, a history of alcoholism, cardiogenic shock, and death $\leq 48 \mathrm{~h}$ after hospitalization. A total of 284 consecutive T2DM patients presenting with STEMI, showed an onset of symptoms $<12 \mathrm{~h}$ were enrolled in the study. Whether the patient stopped taking the metformin during the peri-angiography period depended on the decisions of the physicians at the time. Patients in group 1 continued to take metformin normally while those in group 2 stopped metformin upon admission and restarted it $>48 \mathrm{~h}$ after PCI. Non-ionic, low or equal osmolality contrast agent was used in all patients chosen by each doctor. All patients signed informed consent before enrolled in the study. The study protocol was approved by the institutional ethics committee of Beijing Anzhen Hospital, Capital Medical University.

\section{Data collection}

Data collection regarding cardiovascular risk factors, clinical variables, medication prescriptions and, laboratory values were conducted based on a review of medical records. Cardiovascular risk factors included age, gender, diabetes duration, hyperlipidemia, current smoking, hypertension, etc. Clinical variables included contrast media volume, time to $\mathrm{PCI}$, single-vessel disease, infarct-related artery, etc. The daily metformin dose was recorded and categorized as $>0 \mathrm{~g}$ to $\leq 0.5 \mathrm{~g},>0.5 \mathrm{~g}$ to $\leq 1 \mathrm{~g}$, $>1 \mathrm{~g}$ to $\leq 1.5 \mathrm{~g}$, or $>1.5 \mathrm{~g}$. The medication prescriptions initiated during hospitalization were recorded. Laboratory values, including HbAlc (glycated haemoglobin), $\mathrm{Hb}$ (haemoglobin), cTnI (cardiac troponin I), and creatinine, were collected at admission and after PCI.

\section{Primary outcome}

The study's primary outcome was CI-AKI. The methods for calculating the estimated glomerular filtration rate (eGFR) and incidence of CI-AKI have been described in other articles and are briefly summarized below [2]. The serum creatinine concentration was measured in all patients upon hospital admission and daily in the early 2 days after intracoronary stenting. The highest serum creatinine level within 2 days after coronary angiography was used as post PCI creatinine to diagnose CI-AKI. The diagnostic criteria of CI-AKI was an elevation in serum creatinine $\geq 27 \mu \mathrm{mol} / \mathrm{l}$ or $\geq 50$ per-cent over baseline within $48 \mathrm{~h}$ after contrast media injection [5]. Then the association between continuous metformin therapy in the perioperative period and incidences of CI-AKI was examined.

\section{Secondary outcomes}

The secondary outcomes were (i) the peak blood glucose and insulin initiation therapy within 2 days after primary PCI and (ii) lactic acidosis occurred during hospitalization. 
Capillary glucose was measured at least four times a day during the hospital stay, including once fasting blood glucose and three times postprandial blood glucose, and the peak values within $48 \mathrm{~h}$ after primary PCI for each variable were considered. The peak values of fasting and postprandial blood glucose within $48 \mathrm{~h}$ after primary PCI were compared between the two groups of patients without insulin initiation therapy. Patients with initiated insulin therapy within $48 \mathrm{~h}$ after surgery were recorded, either initiating subcutaneous insulin injection or continuous intravenous insulin. Lactic acidosis was defined as a plasma lactate level of more than $5 \mathrm{mmol} / \mathrm{L}$ and arterial $\mathrm{pH}$ less than 7.35 [2].

\section{Statistical analysis}

All statistical studies were carried out using the SPSS 23.0 program (Chicago, IL, USA). Categorical data were reported as percentages, and continuous data were reported as median $(25-75$ th percentile) or mean $( \pm S D)$. The distribution properties of the data were performed using the Kolmogorov-Smirnov test. Dichotomized data were analyzed for the significant difference using Chi-2 or Fisher's exact test appropriately. Continuous data were analyzed for the significant difference using Student's t or Mann-Whitney test appropriately. Finally, we identified the predictive factors of CI-AKI using logistic regression analysis.

\section{Results}

\section{Baseline characteristics}

Baseline characteristics and patient subgroups, depending on the discontinuation of metformin therapy are summarized in Table 1. According to the physicians' decisions after admission, a total of 119 patients (group 1) did not stop metformin treatment during the periangiography period, and the other 165 patients (group 2) stopped metformin from upon admission and restarted $>48 \mathrm{~h}$ after PCI. There was no statistical difference in both groups for metformin dose. Patients continuing metformin therapy used more beta-blocker. Group 1 patients had cardiovascular risk factors similar to group 2 . Clinical factors, including single-vessel disease and infarct-related artery, were also similar for both groups. Delays of management (time to PCI), left ventricular systolic function, cTnI peak, and glycosylated haemoglobin (HbA1c) values were comparable between the two groups (Table 2).

\section{Kidney function}

We found both baseline eGFR and postoperative eGFR were comparable between the two groups ( $p=0.170$ and $p=0.092$, respectively) (Table 2). Besides, the relative and absolute creatinine changes in patients who continuously used metformin were comparable to those who discontinued metformin after PCI $(p=0.858$ and $p=$ 0.198 , respectively). And it was found that both groups had a similar increase of about $7 \%$ in $\mathrm{Cr}$ values. Furthermore, no statistical difference was shown in the incidence rate of CI-AKI between the two groups (12.6\% VS $10.3 \%$, $p=0.545)$.

\section{Blood glucose control}

Group 2 patients who discontinued metformin treatment showed the higher rate of initiating insulin therapy $\leq 48 \mathrm{~h}$ after primary PCI, whether initiating subcutaneous insulin injection or continuous intravenous insulin ( $p=$ 0.001 and $p=0.021$, respectively) (Table 3 ). In the subgroup of the 207 patients who did not initiate insulin therapy $\leq 48 \mathrm{~h}$ after primary PCI, $102(49 \%)$ continued the metformin therapy. Both fasting and postprandial glucose peaks were significantly higher in patients (51\%) discontinued metformin (7.75[7.10-9.95] VS 9.10[7.30$11.42], 10.65[9.00-12.20]$ VS $13.85[11.90-16.20]$, respectively) (Table 4$)$.

\section{Multiple regression analysis for $\mathrm{Cl}-\mathrm{AKI}$}

Univariate analysis showed that metformin was irrelevant with the increased incidence of CI-AKI after contrast agent exposure. By using multiple regression analysis, we included variables which were significant in univariate analysis, found the presence of contrast volume $(p=$ $0.002)$ and eGFR $\leq 60 \mathrm{ml} / \mathrm{min} / 1.73 \mathrm{~m}^{2}(p=0.025)$ were associated with CI-ÄKI (Table 5).

\section{Discussion}

In this study, the continuous use of metformin for T2DM treatment in STEMI patients, who were submitted to primary $\mathrm{PCI}$, was found reliable concerning the development of CI-AKI. It was also found eGFR $\leq 60$ $\mathrm{ml} / \mathrm{min} / 1.73 \mathrm{~m}^{2}$ and the contrast volume were risk factors of CI-AKI. Besides, discontinuation of metformin results in interruption of hypoglycemic treatment or change of hypoglycemic regimen, and patients presented glucose fluctuation after admission. It was the first study to demonstrate that diabetic patients continuing metformin treatment during primary PCI period were not correlated with CI-AKI.

T2DM is correlated with poor prognosis in patients who have non-obstructive or obstructive stable coronary artery disease. Recent studies demonstrated that diabetes increase mortality and adverse cardiac outcomes in patients with non-obstructive coronary artery stenosis (NOCS)-acute myocardial infarction (AMI) $[15,16]$. Diabetes may favour the plaque instability in the context of NOCS through pathogenetic mechanisms including inflammation, endothelial dysfunction and coronary vasospasm [15]. As a first-line drug for T2DM, metformin has been shown to have cardiovascular benefits and 
Table 1 Cardiovascular risk factors, clinical data and medication (n (\%) or median [IQR]) $(n=284)$

\begin{tabular}{|c|c|c|c|}
\hline metformin & $\begin{array}{l}\text { Metformin } \\
n=119\end{array}$ & $\begin{array}{l}\text { No Metformin } \\
n=165\end{array}$ & $p$ value \\
\hline \multicolumn{4}{|l|}{ Risk factors } \\
\hline Age $\geq 65$ years & $28(23.5 \%)$ & $46(27.9 \%)$ & 0.410 \\
\hline Women & $26(21.8 \%)$ & $47(28.5 \%)$ & 0.207 \\
\hline Diabetes duration $\geq 5$ years & $80(67.2 \%)$ & $99(60.0 \%)$ & 0.430 \\
\hline Hypertension & $74(62.2 \%)$ & $114(69.1 \%)$ & 0.225 \\
\hline Hyperlipidemia & $53(44.5 \%)$ & $61(37.0 \%)$ & 0.199 \\
\hline Current smoking & $80(67.2 \%)$ & $99(60.0 \%)$ & 0.213 \\
\hline Stroke & $8(6.7 \%)$ & $14(8.5 \%)$ & 0.586 \\
\hline Prior myocardial infarction & $16(13.4 \%)$ & $12(7.3 \%)$ & 0.085 \\
\hline PAD & $3(2.5 \%)$ & $4(2.4 \%)$ & 0.959 \\
\hline \multicolumn{4}{|l|}{ Medical therapy initiated during hospitalization } \\
\hline Other oral antihyperglycemic agent. & $60(50.4 \%)$ & $73(44.2 \%)$ & 0.303 \\
\hline ACEI or ARB & $51(42.9 \%)$ & $68(41.2 \%)$ & 0.782 \\
\hline Mineralocorticoid receptor antagonist & $4(3.4 \%)$ & $7(4.2 \%)$ & 0.946 \\
\hline Calcium-channel blocker & $6(5.0 \%)$ & $5(3.0 \%)$ & 0.579 \\
\hline Beta-blocker & $95(79.8 \%)$ & 99 (60\%) & $<0.05$ \\
\hline Metformin dosage & & & 0.230 \\
\hline$>0 \mathrm{~g}$ to $\leq 0.5 \mathrm{~g}$ & $1(0.8 \%)$ & $7(4.2 \%)$ & \\
\hline$>0.5 \mathrm{~g}$ to $\leq 1 \mathrm{~g}$ & $32(26.9 \%)$ & $36(21.8 \%)$ & \\
\hline$>1 \mathrm{~g}$ to $\leq 1.5 \mathrm{~g}$ & $85(71.4 \%)$ & $118(71.5 \%)$ & \\
\hline$>1.5 \mathrm{~g}$ & $1(0.8 \%)$ & $4(2.4 \%)$ & \\
\hline \multicolumn{4}{|l|}{ Clinical data } \\
\hline LVEF $\leq 40 \%$ & $7(5.9 \%)$ & $11(6.7 \%)$ & 0.789 \\
\hline Time to $\mathrm{PCl}$ (hour) & $4(6-16)$ & $6(4-9)$ & 0.139 \\
\hline Single--vessel disease & $31(26.1 \%)$ & $45(27.3 \%)$ & 0.818 \\
\hline \multicolumn{4}{|l|}{ Infarct-related artery } \\
\hline Left main & $0(0 \%)$ & $1(0.6 \%)$ & 1.000 \\
\hline Left anterior descending coronary artery & $56(47.1 \%)$ & $83(50.3 \%)$ & 0.589 \\
\hline Left circumflex coronary artery & $17(14.3 \%)$ & $20(12.1 \%)$ & 0.593 \\
\hline Right coronary artery & $47(39.5 \%)$ & $60(36.4 \%)$ & 0.591 \\
\hline Contrast media volume (ml) & $120(120-200)$ & $150(110-200)$ & 0.884 \\
\hline
\end{tabular}

$P A D$ peripheral arterial disease, $A C E I$ angiotensin-converting enzyme inhibitor, $A R B$ angiotensin receptor blocker, $L V E F$ left ventricular ejection fraction, $P C I$ percutaneous coronary intervention

fewer adverse reactions [17]. Current guidelines suggest that prediabetes should also be treated with metformin to mitigate the risk of developing diabetes. A recent study by Celestino et al. found that metformin therapy may improve adverse cardiovascular outcomes in prediabetes patients by reducing coronary endothelial dysfunction. The improvement in endothelial dysfunction is attributed to metformin downregulating the inflammation/ oxidative stress in the context of NOCS [18]. Besides, metformin therapy for prediabetes may improve outcomes by a reduction of inflammatory tone and leptin to adiponectin rate in peri-coronary fat in AMI patients [19]. There is increasing evidence that specific hypoglycemic drugs with pleiotropic effect on inflammatory tone and oxidative stress may affect the control of atherosclerotic plaque progression in AMI patients [15].

Patients presenting with STEMI are prone to develop CI-AKI after primary PCI, and high thrombogenic state and inflammation are among the leading causes [5]. Hyperglycemic patients presenting with STEMI have higher coronary thrombus burden compared with thrombi from normoglycemic counterparts. Evidence showed that hyperglycemia causes overproduction of 
Table 2 Laboratory data and incidence of Cl-AKI (n (\%) or median [IQR]) $(n=284)$

\begin{tabular}{|c|c|c|c|}
\hline & $\begin{array}{l}\text { metformin } \\
n=119\end{array}$ & $\begin{array}{l}\text { No Metformin } \\
n=165\end{array}$ & $p$ value \\
\hline $\mathrm{HbA} 1 \mathrm{c}(\%)$ & $7.0[3.6-14.2]$ & $7.8[6.9-8.8]$ & 0.194 \\
\hline $\mathrm{Hb}(\mathrm{g} / \mathrm{l})$ & 141 [126-152] & 120 [110-140] & 0.079 \\
\hline cTnl peak (ng/ml) & $7.0[3.6-14.2]$ & $7.8[6.9-8.8]$ & 0.842 \\
\hline \multicolumn{4}{|l|}{ Creatinine } \\
\hline Baseline $(\mu \mathrm{mol} / \mathrm{l})$ & $76[66-86]$ & $73[61-84]$ & 0.105 \\
\hline Post PCI ( $\mu \mathrm{mol} / \mathrm{l})$ & 83 [72-98] & $76[64-76]$ & 0.012 \\
\hline Relative creatinine change & $11 \%[6-20 \%]$ & $11 \%[5-22 \%]$ & 0.858 \\
\hline \multicolumn{4}{|l|}{ post PCI (\%) } \\
\hline$\geq 50 \%$ increase & $5(4.2 \%)$ & $9(5.5 \%)$ & 0.630 \\
\hline Absolute creatinine change & $7.9[2.4-13.2]$ & $6.7[0.2-12.7]$ & 0.198 \\
\hline \multicolumn{4}{|l|}{ post PCl (\%) ( $\mu \mathrm{mol} / \mathrm{l})$} \\
\hline$\geq 27 \mu \mathrm{mol} /(0.3 \mathrm{mg} / \mathrm{dl})$ & $15(12.6 \%)$ & 15 (9.1\%) & 0.342 \\
\hline \multicolumn{4}{|l|}{$\mathrm{eGFR}\left(\mathrm{ml} / \mathrm{min} / 1.73 \mathrm{~m}^{2}\right)$} \\
\hline Baseline $\left(\mathrm{ml} / \mathrm{min} / 1.73 \mathrm{~m}^{2}\right)$ & 89 [73-104] & 94 [72-113] & 0.170 \\
\hline $\mathrm{eGFR} \leq 60 \mathrm{ml} / \mathrm{min} / 1.73 \mathrm{~m}^{2}$ & $9(7.6 \%)$ & $21(12.7 \%)$ & 0.163 \\
\hline Post PCI (ml/min/1.73m²) & 77 [65-95] & 87 [67-102] & 0.092 \\
\hline Relative eGFR change & $13.4 \%$ [6.4-25.1\%] & $13.5 \%$ [5.2-24.3\%] & 0.449 \\
\hline \multicolumn{4}{|l|}{ post PCI (\%) } \\
\hline Absolute eGFR change & $-7[-16 ; 3]$ & $-6[-18 ; 3]$ & 0.981 \\
\hline \multicolumn{4}{|l|}{ post $\mathrm{PCl}\left(\mathrm{ml} / \mathrm{min} / 1.73 \mathrm{~m}^{2}\right)$} \\
\hline Cl-AKI & $15(12.6 \%)$ & $17(10.3 \%)$ & 0.545 \\
\hline
\end{tabular}

HbA1c glycosylated hemoglobin, $\mathrm{Hb}$ hemoglobin, eGFR glycosylated hemoglobin estimated glomerular filtration rate, $c T$ I cardiac troponin I, $P C l$ percutaneous coronary intervention, Cl-AKI contrast induced-acute renal injury

reactive oxygen species and inflammation from thrombus plaque, favouring thrombotic embolization and poor myocardial infarction outcomes. The miR33/ sirtuin 1 pathway have been demonstrated to play a part in promoting inflammatory and coagulation of coronary thrombi in STEMI patients during hyperglycaemia [20, 21]. In this context, whether metformin in diabetic patients with STEMI undergoing coronary angiography should be discontinued, has been discussed because of its postprocedural risks, including CI-AKI and MALA. Advice on the discontinuation of metformin differs between guidelines [7-10, 22]. European Society of Urogenital Radiology guideline recommends stopping metformin directly from the time of contrast media administration [10], while European Society of Cardiology guidelines recommends checking renal function after angiography for at least 3 days and withhold metformin when renal function is deteriorated
[8]. There are few studies about metformin used in patients with mildly impaired kidney function after the administration of contrast agents. In the two latest randomized controlled studies, the patients continuing metformin during peri-angiography does not carry the excess risk for renal dysfunction. No lactic acidosis is observed in both studies $[23,24]$. Currently, the influence of metformin on the kidney function in STEMI patients is widely discussed. The GIPS III trial has supported the idea that metformin is safe to use after STEMI and contrast agent exposure. Nondiabetic patients started metformin therapy within $3 \mathrm{~h}$ after the coronary intervention had no harmful effect on kidney functions [11]. In addition, a multi-centre observational study has shown that chronic metformin treatment before PCI has no significant effect on CI-AKI in T2DM patients with STEMI [2]. Those studies strongly suggested that metformin is not related to an increased risk of renal

Table 3 Initiate Insulin therapy $\leq 48 \mathrm{~h}$ after primary PCl

\begin{tabular}{llll}
\hline & $\begin{array}{l}\text { metformin } \\
n=119\end{array}$ & $\begin{array}{l}\text { No Metformin } \\
n=165\end{array}$ & $p$ value \\
\hline initiate continuous intravenous insulin & $2(1.68 \%)$ & $13(7.88 \%)$ & 0.021 \\
Initiate subcutaneous insulin injection & $15(12.61 \%)$ & $47(28.48 \%)$ & 0.001 \\
\hline
\end{tabular}


Table 4 Blood glucose control $\leq 48 \mathrm{~h}$ after primary PCI (excluded patients initiating insulin therapy $\leq 48 \mathrm{~h}$ after primary PCl)

\begin{tabular}{lllr}
\hline & metformin & No Metformin & $p$ value \\
& $n=102$ & $n=105$ & $<0.05$ \\
\hline fasting glucose peak (mmol/l) & $7.75[7.10-9.95]$ & $9.10[7.30-11.42]$ & 0.02 \\
postprandial glucose peak (mmo//) & $10.65[9.00-12.20]$ & $13.85[11.90-16.20]$ & \\
\hline
\end{tabular}

dysfunction after coronary angiography. The hypothesis that AMI patients may use metformin safely during the peri-angiography period was further reinforced. Our research is consistent with the above studies. The present data indicated that both absolute and relative creatinine change after PCI were similar between the patients continuing metformin therapy and those suspending metformin therapy. By multivariate analysis, metformin was not related to $\mathrm{CI}-\mathrm{AKI}$, whereas contrast volume $(p=0.002)$ and eGFR $\leq 60 \mathrm{ml} / \mathrm{min} / 1.73 \mathrm{~m}^{2}(p<0.025)$ were indicated to be predictive factors of CI-AKI.

Several studies have demonstrated that the contrast agent volume is associated with the morbidity of acute kidney injury [25]. The nephrotoxicity of iodinated contrast media may be proportional to the dose for coronary angiography. The main causes of CI-AKI have been proposed, including renal medullary hypoxia caused by hemodynamic instability, oxidative stress and direct toxicity on kidney tubular epithelial cells [26-28]. It was important to understand that using a lower dose of contrast agent may substantially reduce the CI-AKI risk of patients. Patients with chronic kidney disease have fewer nephron units than normal, so exposure to the same volume of contrast media will significant increased proportionally. Because of their low adaptive capacity and increased contrast agent exposure, they are more susceptible to develop CI-AKI [27].

As metformin is eliminated by the kidneys, there are concerns that in patients with the reduced kidney function, the lactic acidosis will be accumulated and precipitated [29]. However, the strength of the relationship between metformin and lactic acidosis has been dramatically overstated [4]. Several clinical studies have shown that there is no significant correlation between metformin concentration and lactic acidosis [1, 4, 30-32]. Furthermore, the current study and meta-analyses show that the morbidity of lactic acidosis using metformin is not significantly different from other hypoglycemic treatments, such as sulfonylureas, insulin, and other oral hypoglycemic agents [33-39]. Other studies have also shown that metformin concentrations remain in a therapeutic range in mildly to moderately renal impaired patients [40]. At the same time, growing evidence suggests that the underlying disease associated with the tissue hypoxia rather than metformin use is related to lactic acidosis in diabetes [41-43]. In the present research, no case of lactic acidosis was observed during hospitalization for both groups.

Hyperglycemia has been linked with more complications during hospitalization and poor outcomes in AMI patients. Lazzeri et al. [44] concluded that in STEMI patients, in-hospital peak glycemia is negatively correlated with long-term survival. Besides that, another study had also confirmed that acute hyperglycemia is a predictor of CI-AKI and in-hospital mortality [45]. Peri-procedural tight glycemic control has been shown to significantly increase the area of myocardial salvage following a great recovery of left ventricular function in hyperglycemic patients undergoing emergency coronary intervention for STEMI. These observations strongly suggest that the tight glycemic control at the time of the PCI may be pursued in the STEMI patients to improve their prognosis [46]. Therefore, strict glucose management in STEMI patients with mildly impaired renal function is recommended during a hospital stay [47]. In this research, we found the patients who discontinued metformin treatment, were more likely to initiate insulin therapy and had higher peak glycemia. Our data indicated that the patients who stopped metformin were inclined to have blood glucose fluctuation and changes in hypoglycemic regimens after admission.

Table 5 Single-factor and multiple-factor regression analysis of $\mathrm{Cl}$-AKI

\begin{tabular}{|c|c|c|c|c|}
\hline \multirow[t]{2}{*}{ Factor } & \multicolumn{2}{|l|}{ Single-factor } & \multicolumn{2}{|l|}{ Multiple-factor } \\
\hline & OR $(95 \% \mathrm{Cl})$ & $\mathrm{p}$ & OR $(95 \% \mathrm{Cl})$ & $\mathrm{p}$ \\
\hline Metformin & $0.796(0.381,1.666)$ & 0.546 & $0.698(0.320,1.521)$ & 0.365 \\
\hline Metformin dose & $0.787(0.413,1.500)$ & 0.467 & $0.658(0.336,1.288)$ & 0.222 \\
\hline $\mathrm{eGFR} \leq 60 \mathrm{ml} / \mathrm{min} / 1.73 \mathrm{~m}^{2}$ & $2.788(1.087,7.147)$ & 0.033 & $3.131(1.156,8.482)$ & 0.025 \\
\hline Contrast media volume (ml) & $1.009(1.004,1.015)$ & 0.002 & $1.010(1.004,1.016)$ & 0.002 \\
\hline
\end{tabular}

CI-AKI contrast induced-acute renal injury, eGFR glycosylated hemoglobin estimated glomerular filtration rate 
Unlike previous studies, our study focused on the effect of perioperative use of metformin on renal function, with one group continued metformin treatment after primary PCI and another discontinued it $>48 \mathrm{~h}$ after the primary $\mathrm{PCI}$, which is different from Zeller's [2] work, and this is a major contribution of our work. The application of metformin in the peri-angiography period in the existing guidelines is not yet consistent; our study focused on this situation and target at patients who are inclined to develop CI-AKI. The result of the study indicated that continued use of metformin did not impair renal function compared to discontinuation of metformin during primary PCI period. In real clinical practice, we found that discontinuous use of metformin caused problems in blood glucose management in STEMI patients after admission. The patients who stopped metformin were more likely to have blood glucose fluctuation and changes in hypoglycemic regimens after PCI. The peak values of fasting and postprandial blood glucose in patients with discontinuous metformin treatment were significantly higher than those of patients receiving metformin continuously. Previous studies have confirmed that peak glycemia during hospitalization is negatively correlated with the long-term survival in diabetic STEMI patients [39]. To summarize the above findings, continuous use of metformin during coronary angiography may not raise the risk of CI-AKI, and the blood glucose of patients after admission will be better controlled, which is conducive to the prognosis of STEMI patients.

This study had the following two limitations. Firstly, it was a retrospective cohort study, conducted at a single centre, based on a relatively small size of populations. Secondly, since the high-risk patients such as those who needed intraaortic balloon pump, or had respiratory failure were excluded, the results in this paper may not be adapted to these subgroups of patients. However, it was believed that the findings are of clinical significance in most patients.

\section{Conclusions}

The present results indicated that the continuous use of metformin after PCI for STEMI in diabetic patients with GFR $>30 \mathrm{ml} / \mathrm{min} / 1.73 \mathrm{~m}^{2}$ may not enhance the risk of CI-AKI. Upon multivariable adjustment, eGFR $\leq 60 \mathrm{ml} /$ $\min / 1.73 \mathrm{~m}^{2}$ and contrast agent dose were linked with CIAKI after primary PCI, while the continuous metformin treatment was not. Besides that, the patients who discontinued metformin treatment showed an increased rate of initiating insulin therapy and higher peak glycemia within $48 \mathrm{~h}$ after primary PCI.

\footnotetext{
Abbreviations

STEMI: ST-segment elevation myocardial infarction; PCl: Percutaneous coronary intervention; Cl-AKl: Contrast induced-acute kidney injury; eGFR: Estimated glomerular filtration rate; T2DM: Type 2 diabetes mellitus; MALA: Metformin associated with lactic acidosis; PAD: Peripheral arterial disease; LVEF: Left ventricular ejection fraction; ACEl: Angiotensin-converting enzyme inhibitor; ARB: Angiotensin receptor blockers; HbA1c: Glycated
}

haemoglobin; Hb: Haemoglobin; cTnl: Cardiac troponin I; NOCS: Nonobstructive coronary artery stenosis; AMl: Acute myocardial infarction

\section{Acknowledgements}

Not applicable.

\section{Authors' contributions}

QY participated in the trail design, collected and analyzed the data, and wrote the article. JJZ participated in the experiment design. WXL is the corresponding author who participated in the trial design and reviewed the article. All authors read and approved the final manuscript.

\section{Funding}

This work was supported by the Beijing Health and technology achievements for technology promotion project (TG-2017-34). The funding body played no role in the design of the study and collection, analysis, and interpretation of data and in writing the manuscript. The funding body only provided the financial means to allow the authors to carry out the study.

\section{Availability of data and materials}

The datasets during and/or analysed during the current study available from the corresponding author on reasonable request.

\section{Ethics approval and consent to participate}

All patients signed informed consent before enrolled in the study. The study protocol was approved by the institutional ethics committee of Beijing Anzhen Hospital, Capital Medical University. IRB (Ethical Committee) approval number:2019041X

\section{Consent for publication}

Not applicable.

\section{Competing interests}

The authors declare that they have no competing interests.

Received: 6 December 2019 Accepted: 12 April 2020

Published online: 21 April 2020

\section{References}

1. Aharaz A, Pottegard A, Henriksen DP, Hallas J, Beck-Nielsen H, Lassen AT. Risk of lactic acidosis in type 2 diabetes patients using metformin: A case control study. PLoS One. 2018;13(5):e0196122.

2. Zeller M, Labalette-Bart M, Juliard J-M, Potier L, Feldman L, Steg PG, Cottin $Y$, Roussel R. Metformin and contrast-induced acute kidney injury in diabetic patients treated with primary percutaneous coronary intervention for ST segment elevation myocardial. Int J Cardiol. 2016;220:137-42.

3. Fitzgerald E, Mathieu S, Ball A. Lesson of the week metformin associated lactic acidosis. BMJ. 2009:339. https://doi.org/10.1136/bmj.b3660.

4. De Broe ME, Kajbaf F, Lalau J-D. Renoprotective effects of metformin. Nephron. 2018:138(4):261-74.

5. Silvain J, Nguyen LS, Spagnoli V, Kerneis M, Guedeney P, Vignolles N, Cosker K, Barthelemy O, Le Feuvre C, Helft G, et al. Contrast-induced acute kidney injury and mortality in ST elevation myocardial infarction treated with primary percutaneous coronary intervention. Heart. 2018;104(9):767-72.

6. Cinar T, Karabag Y, Ozan Tanik V, Cagdas M, Rencuzogullari I, Oz A. The investigation of TIMI risk index for prediction of contrast-induced acute kidney injury in patients with ST elevation myocardial infarction. Acta Cardiol. 2019;75:1-8

7. Roffi M, Patrono C, Collet JP, Mueller C, Valgimigli M, Andreotti F, Bax Jر Borger MA, Brotons C, Chew DP, et al. 2015 ESC guidelines for the management of acute coronary syndromes in patients presenting without persistent ST-segment elevation task force for the Management of Acute Coronary Syndromes in patients presenting without persistent ST-segment elevation of the European Society of Cardiology (ESC). Eur Heart J. 2016; 37(3):267.

8. Ibanez B, James S, Agewall S, Antunes MJ, Bucciarelli-Ducci C, Bueno H, Caforio ALP, Crea F, Goudevenos JA, Halvorsen S, et al. 2017 ESC guidelines for the management of acute myocardial infarction in patients presenting with ST-segment elevation the task force for the management of acute myocardial infarction in patients presenting with ST-segment elevation of the European Society of Cardiology (ESC). Eur Heart J. 2018;39(2):119-77. 
9. Stacul F, van der Molen AJ, Reimer P, Webb JAW, Thomsen HS, Morcos SK, Almen T, Aspelin P, Bellin M-F, Clement O, et al. Contrast induced nephropathy: updated ESUR contrast media safety committee guidelines. Eur Radiol. 2011;21(12):2527-41.

10. van der Molen AJ, Reimer P, Dekkers IA, Bongartz G, Bellin M-F, Bertolotto M, Clement O, Heinz-Peer G, Stacul F, Webb JAW, et al. Post-contrast acute kidney injury. Part 2: risk stratification, role of hydration and other prophylactic measures, patients taking metformin and chronic dialysis patients. Eur Radiol. 2018;28(7):2856-69.

11. Posma RA, Lexis CPH, Lipsic E, Nijsten MWN, Damman K, Touw DJ, van Veldhuisen DJ, van der Harst P, van der Horst ICC. Effect of metformin on renal function after primary percutaneous coronary intervention in patients without Diabetes presenting with ST-elevation myocardial infarction: data from the GIPS-III trial. Cardiovasc Drugs Ther. 2015;29(5):451-9.

12. Tziakas D, Chalikias G, Stakos D, Altun A, Sivri N, Yetkin E, Gur M, Stankovic G, Mehmedbegovic Z, Voudris V, et al. Validation of a new risk score to predict contrast-induced nephropathy after percutaneous coronary intervention. Am J Cardiol. 2014;113(9):1487-93.

13. Tziakas D, Chalikias G, Stakos D, Apostolakis S, Adina T, Kikas P, Alexoudis A, Passadakis $P$, Thodis $E$, Vargemezis $V$, et al. Development of an easily applicable risk score model for contrast-induced nephropathy prediction after percutaneous coronary intervention a novel approach tailored to current practice. Int J Cardiol. 2013;163(1):46-55.

14. American Diabetes A. 2. Classification and diagnosis of Diabetes: standards of medical Care in Diabetes-2019. Diabetes Care. 2019; 42(Suppl 1):S13-28.

15. Marfella R, Sardu C, Balestrieri ML, Siniscalchi M, Minicucci F, Signoriello G, Calabro P, Mauro C, Pieretti G, Coppola A, et al. Effects of incretin treatment on cardiovascular outcomes in diabetic STEMI-patients with culprit obstructive and multivessel non obstructive-coronary-stenosis. Diabetol Metab Syndr. 2018;10:1.

16. Marfella R, Sardu C, Calabro P, Siniscalchi M, Minicucci F, Signoriello G, Balestrieri ML, Mauro C, Rizzo MR, Paolisso G, et al. Non-ST-elevation myocardial infarction outcomes in patients with type 2 diabetes with nonobstructive coronary artery stenosis: effects of incretin treatment. Diabetes Obes Metab. 2018;20(3):723-9.

17. Lazarus B, Wu A, Shin J-I, Sang Y, Alexander GC, Secora A, Inker LA, Coresh J, Chang AR, Grams ME. Association of Metformin use with Risk of lactic acidosis across the range of kidney function a community-based cohort study. JAMA Intern Med. 2018;178(7):903-10.

18. Sardu C, Paolisso P, Sacra C, Mauro C, Minicucci F, Portoghese M, Rizzo MR, Barbieri M, Sasso FC, D'Onofrio N, et al. Effects of metformin therapy on coronary endothelial dysfunction in patients with Prediabetes with stable angina and nonobstructive coronary artery stenosis: the CODYCE multicenter prospective study. Diabetes Care. 2019;42(10):1946-55.

19. Sardu C, D'Onofrio N, Torella M, Portoghese M, Loreni F, Mureddu S, Signoriello G, Scisciola L, Barbieri M, Rizzo MR, et al. Pericoronary fat inflammation and Major Adverse Cardiac Events (MACE) in prediabetic patients with acute myocardial infarction: effects of metformin. Cardiovasc Diabetol. 2019;18(1):123.

20. D'Onofrio N, Sardu C, Paolisso P, Minicucci F, Gragnano F, Ferraraccio F, Panarese I, Scisciola L, Mauro C, Rizzo MR, et al. MicroRNA-33 and SIRT1 influence the coronary thrombus burden in hyperglycemic STEMI patients. Cell Physiol. 2020;235(2):1438-52.

21. Sardu C, Barbieri M, Balestrieri ML, Siniscalchi M, Paolisso P, Calabro $P$, Minicucci F, Signoriello G, Portoghese M, Mone P, et al. Thrombus aspiration in hyperglycemic ST-elevation myocardial infarction (STEMI) patients: clinical outcomes at 1-year follow-up. Cardiovasc Diabetol. 2018;17:512.

22. Neumann F-J, Chettibi M, Sisakia H, Metzler B, Ibrahimov F, Stelmashok VI, Postadzhiyan A, Skoric B, Eftychiou C, Kala P, et al. 2018 ESC/EACTS guidelines on myocardial revascularization. Eur Heart J. 2019;40(2):87.

23. Namazi MH, AlipourParsa S, Roohigilani K, Safi M, Vakili H, Khaheshi I, Abdi F, Zare A, Esmaeeli S. Is it necessary to discontinue metformin in diabetic patients with GFR $>60 \mathrm{ml} / \mathrm{min}$ per $1.73 \mathrm{~m} 2$ undergoing coronary angiography: a controversy still exists? Acta Biomed. 2018;89(2):227-32.

24. Oktay V, Cirali IC, Sinan UY, Yildiz A, Ersanli MK. Impact of continuation of metformin prior to elective coronary angiography on acute contrast nephropathy in patients with normal or mildly impaired renal functions. Anatol J Cardiol. 2017;18(5):334-9.

25. Mehran R, Aymong ED, Nikolsky E, Lasic Z, lakovou I, Fahy M, Mintz GS, Lansky AJ, Moses JW, Stone GW, et al. A simple risk score for prediction of contrast-induced nephropathy after percutaneous coronary intervention development and initial validation. J Am Coll Cardiol. 2004;44(7):1393-9.

26. McCullough PA, Choi JP, Feghali GA, Schussler JM, Stoler RM, Vallabahn RC, Mehta A. Contrast-induced acute kidney injury. J Am Coll Cardiol. 2016: 68(13):1465-73.

27. Mamoulakis C, Tsarouhas K, Fragkiadoulaki I, Heretis I, Wilks MF, Spandidos DA, Tsitsimpikou C, Tsatsakis A. Contrast-induced nephropathy: basic concepts, pathophysiological implications and prevention strategies. Pharmacol Ther. 2017;180:99-112.

28. Faehling M, Seeliger E, Patzak A, Persson PB. Understanding and preventing contrast-induced acute kidney injury. Nat Rev Nephrol. 2017;13(3):169-80.

29. Gulli G. Lactic acidosis, metformin use, and dose-RESPONSE association RESPONSE. JAMA Intern Med. 2018;178(10):1428.

30. Lim VCC, Sum CF, Chan ESY, Yeoh LY, Lee YM, Lim SC. Lactate levels in Asian patients with type 2 diabetes mellitus on metformin and its association with dose of metformin and renal function. Int J Clin Pract. 2007:61(11):1829-33.

31. Kajbaf F, Lalau JD. The criteria for metformin-associated lactic acidosis: the quality of reporting in a large pharmacovigilance database. Diabet Med. 2013;30(3):345-8.

32. Stades AME, Heikens JT, Erkelens DW, Holleman F, Hoekstra JBL. Metformin and lactic acidosis: cause or coincidence? A review of case reports. J Intern Med. 2004:255(2):179-87.

33. Cryer DR, Nicholas SP, Henry DH, Mills DJ, Stadel BV. Comparative outcomes study of metformin intervention versus conventional approach - the COSMIC approach study. Diabetes Care. 2005;28(3):539-43.

34. Bodmer M, Meier C, Kraehenbuehl S, Jick SS, Meier CR. Metformin, sulfonylureas, or other Antidiabetes drugs and the risk of lactic acidosis or hypoglycemia a nested case-control analysis. Diabetes Care. 2008;31(11):2086-91.

35. Ekstrom N, Schioler L, Svensson AM, Eeg-Olofsson K, Jonasson JM, Zethelius B, Cederholm J, Eliasson B, Gudbjornsdottir S. Effectiveness and safety of metformin in 51675 patients with type 2 diabetes and different levels of renal function: a cohort study from the Swedish National Diabetes Register. BMJ Open. 2012;2(4):10.

36. Trinkley KE, Anderson HD, Nair KV, Malone DC, Saseen JJ. Assessing the incidence of acidosis in patients receiving metformin with and without risk factors for lactic acidosis. Ther Adv Chronic Dis. 2018;9(9):179-90.

37. Salpeter SR, Greyber E, Pasternak GA, Salpeter EE. Risk of fatal and nonfatal lactic acidosis with metformin use in type 2 diabetes mellitus - systematic review and meta-analysis. Arch Intern Med. 2003;163(21):2594-602.

38. Salpeter S, Greyber E, Pasternak G, Salpeter E. Risk of fatal and nonfatal lactic acidosis with metformin use in type 2 diabetes mellitus. Cochrane Database Syst Rev. 2006;25(1):CD002967.

39. Salpeter SR, Greyber E, Pasternak GA, Salpeter EE. Risk of fatal and nonfatal lactic acidosis with metformin use in type 2 diabetes mellitus. Cochrane Database Syst Rev. 2010;20(1):CD002967.

40. Jung J, Cho YY, Jung JH, Kim KY, Kim HS, Baek JH, Hahm JR, Cho HS, Kim SK. Are patients with mild to moderate renal impairment on metformin or other oral anti-hyperglycaemic agents at increased risk of contrast-induced nephropathy and metabolic acidosis after radiocontrast exposure? Clin Radiol. 2019;74(8):651.e1-6.

41. Lalau JD, Race JM. Lactic acidosis in metformin-treated patients - prognostic value of arterial lactate levels and plasma metformin concentrations. Drug Saf. 1999;20(4):377-84

42. Kim MJ, Han JY, Shin JY, Kim SI, Lee JM, Hong S, Kim SH, Nam MS, Kim YS Metformin-associated lactic acidosis: predisposing factors and outcome. Endocrinol Metab (Seoul). 2015;30(1):78-83.

43. Lee EY, Hwang S, Lee YH, Lee SH, Lee YM, Kang HP, Han E, Lee W, Lee B-W, Kang ES, et al. Association between metformin use and risk of lactic acidosis or elevated lactate concentration in type 2 Diabetes. Yonsei Med J. 2017; 58(2):312-8.

44. Lazzeri C, Valente S, Chiostri M, Attana P, Picariello C, Gensini GF. The prognostic role of in-hospital peak glycemia in stemi patients with and without diabetes. Acta Diabetol. 2012:49(5):379-86.

45. Marenzi G, De Metrio M, Rubino M, Lauri G, Cavallero A, Assanelli E, Grazi M, Moltrasio M, Marana I, Campodonico J, et al. Acute hyperglycemia and contrast-induced nephropathy in primary percutaneous coronary intervention. Am Heart J. 2010;160(6):1170-7.

46. Marfella R, Rizzo MR, Siniscalchi M, Paolisso P, Barbieri M, Sardu C, Savinelli A, Angelico N, Del Gaudio S, Esposito N, et al. Peri-procedural tight glycemic control during early percutaneous coronary intervention up-regulates 
endothelial progenitor cell level and differentiation during acute ST-

elevation myocardial infarction: effects on myocardial salvage. Int J Cardiol. 2013;168(4):3954-62.

47. Lazzeri C, Valente S, Chiostri M, Nesti M, D'Alfonso MG, Gensini GF. Prognostic

role of glucose abnormalities in patients with ST-elevation myocardial

infarction and mild renal impairment. Int J Cardiol. 2014;171(2):E26-7.

\section{Publisher's Note}

Springer Nature remains neutral with regard to jurisdictional claims in published maps and institutional affiliations.

Ready to submit your research? Choose BMC and benefit from:

- fast, convenient online submission

- thorough peer review by experienced researchers in your field

- rapid publication on acceptance

- support for research data, including large and complex data types

- gold Open Access which fosters wider collaboration and increased citations

- maximum visibility for your research: over $100 \mathrm{M}$ website views per year

At $B M C$, research is always in progress.

Learn more biomedcentral.com/submissions 